1. Киреева Н.А., Сухорукова А.М. Обеспечение экономического суверенитета России в агропродовольственной сфере: тенденции, проблемы, инструменты // Аграрный научный журнал. - 2017. - № 1. - С. 66-74.

2. Кружилин И.П. Комплексная мелиорация земель обеспечит устойчивое развитие сельского хозяйства Поволжья // Вестник Российской академии с.-х. наук. - 2011. - № 1. - С. 14-16.

3. Несмысленов А.П. Организационно-экономические факторы повышения эффективности использования орошаемых земель / ФГБНУ «ПНИИЭО АПК». - Саратов: Издательство «Саратовский источник», 2016. - 387 с.

4. Несмысленов А.П., Санникова М.О. Повышение эффективности использования производственного потенциала на основе модернизации основных фондов орошаемого земледелия // Научное обозрение: теория и практика. - 2016. - № 1. - С. 93-101.

5. Нечаев В.И., Васильева Н.К., Фетисов С.Д. Оценка устойчивости развития аграрного сектора // Экономика сельского хозяйства России. - 2010. - № 2. - С. 52-62.

6. Основные задачи природного обоснования устойчивого развития оросительных мелиораций / Б.Б. Шумаков [и др.] // Проблемы гидрогеологии, инженерной геологии и почвоведения: сборник. - М.: ВНИИГиМ, 1996. - С. 21-30.

7. Повышение эффективности сельскохозяйс- твенного землепользования в орошаемом земледелии / А.П. Несмысленов [и др.] // Организационно-экономический механизм устойчивого развития агропромышленного комплекса и сельских территорий в Поволжье / Е.Ф. Заворотин [и др.]; ФГБНУ «ПНИИЭО АПК». - Саратов: Издательство «Саратовский источник», 2017. - С. 55-82.

8. Форрестер Д. Мировая динамика / пер. с англ. - М: ООО «Издательство АСТ»; СПб.: Terra Fantastica, 2003. - 379 c.

9. Щедрин В.Я., Балакай Г.Т. Мелиорация земель основа устойчивого развития АПК России // Вестник аграрной науки Дона. - 2010. - № 3. - С. 98-107.

10. Экономические проблемы инновационного развития / А.А. Пороховский [и др.]; под ред. К.А. Хубиева. - М.: ТЕИС, 2009. - С. 699.

Несмыслёнов Александр Павлович, канд. экон. наук, главный научный сотрудник сектора развития мелиорации, Поволжский научно-исследовательский институт экономики и организации АПК. Россия.

Новикова Светлана Михайловна, канд. с.-х. наук, старший научный сотрудник сектора развития мелиорации, Поволжский научно-исследовательский институт экономики и организации АПК. Россия.

410010, г. Саратов, ул. Шехурдина, 12.

Тел.: (8452) 64-06-47; e-mail:nii_apk_sar@mail.ru.

Ключевые слова: орошаемое земледелие; устойчивое функционирование; эффективность производственного потенцииала; элементы устойчивости.

\title{
POTENTIAL OF IRRIGATED AGRICULTURE IS THE BASIS OF SUSTAINABLE FUNCTIONING OF THE SECTOR
}

Nesmyslenov Aleksandr Pavlovich, Candidate of Economic Sciences, Chief Researcher of Amelioration Development Sector, Volga Research Institute of Economy and Organization of Agro-Industrial Complex. Russia.

Novikova Svetlana Mikhaylovna, Candidate of Agricultural Sciences, Senior Researcher of Amelioration Development Sector, Volga Research Institute of Economy and Organization of Agro-Industrial Complex. Russia.

Keywords: irrigated agriculture; sustainable functioning; efficiency of production potential; elements of sustainability.

In article approaches to development of methods of steady functioning of the irrigated agriculture from positions of a re- search of capacity of the irrigated lands are formulated. The possibility of increase in efficiency of use of production potential as basic element of sustainable development of irrigating melioration and functioning of the irrigated agriculture, on the basis of use of separate provisions of the theory of $D$. Forrester - D. Meadows is considered. Development of methods of steady functioning of the irrigated lands and validity of their application is based on a basis of understanding of a method as the set of methods and operations directed to growth of return from the resources involved in production, and providing steady functioning of the economic entities which are engaged in production of crop production in the conditions of irrigation.

\section{РАЗВИТИЕ СЕЛЬСКОХОЗЯЙСТВЕННЫХ И ПЕРЕРАБАТЫВАЮЩИХ ПРЕДПРИЯТИЙ: ПРОБЛЕМЫ В СВЕТЕ ИЗМЕНЕНИЯ НАЛОГОВОГО ЗАКОНОДАТЕЛЬСТВА РФ}

\section{СУХАНОВА Ирина Федоровна, Саратовский государственный аграрный университет имени} Н.И. Вавилова

\section{АЛИЕВ Максим Игоревич, ООО «Торговая группа Союз»}

Рассмотрены различные варианты систем налогообложения, применяющиеся предприятиями агропромышленного комплекса. Произведен анализ последствий изменений фискального законодательства в части системы взимания единого сельскохозяйственного налога. Изучены макроэкономические последствия введения системы налогообложения с использованием налога на добавленную стоимость по принципу «от поля до прилавка».

Введение. Специальные налоговые режимы являются действенными инструментами государственной политики многих стран, направленными на поддержку и развитие аграрных и продовольственных отраслей. При этом их при- менение, если оно не приводит к дискриминации или поощрению производителей, экспортеров или импортеров определенных товаров, является допустимым с точки зрения общих правил Всемирной торговой организации (ВТО). 
Например, вот уже более десяти лет с 2005 г. все отечественные сельскохозяйственные организации могли по своему выбору воспользоваться специальным налоговым режимом, установленным главой 26.1 Налогового кодекса РФ, единым сельскохозяйственным налогом (ЕСXН) [5]. В 2017 г. Правительство Российской Федерации анонсировало ряд ключевых изменений налогового законодательства, касающихся предприятий агропромышленного комплекса. В конце года все эти изменения были законодательно оформлены и с 2018 г. вступили в силу, что обусловливает необходимость исследования предстоящих последствий от реализации нововведений для аграрной отрасли России.

Методика исследований. Для анализа экономического содержания и последствий введения различных систем налогообложения, а также новых видов специальных налоговых режимов и их экономической эффективности необходимо использовать основные подходы системного анализа, в том числе структуралистский, воспроизводственный, а также генетический и институциональный подходы. Теоретическиеиметодологическиеосновыисследования включают как работы российских ученых $[2,4,9,10]$, так и нормативно-правовые документы. Предлагаемые методы исследования: экономико-статистические, используемые для оценки степени влияния произошедших изменений российского налогового законодательства на предприятия АПК; расчетно-конструктивный метод; метод сравнительного анализа и экспертных оценок. Помимо специфических методов использованы всеобщие и общенаучные подходы: диалектика, абстрагирование, дедукция, индукция, анализ и синтез.

В ходе работы была собрана фактическая информация о применении сельскохозяйственными и перерабатывающими предприятиями различных систем налогообложения, предусмотренных Налоговым кодексом РФ. Для оценки степени влияния произошедших изменений российского налогового законодательства на предприятия АПК был произведен анализ изданных нормативно-правовых актов в сфере государственной фискальной политики. В итоге были синтезированы выводы о последствиях принятых изменений для агропромышленного комплекса России в контексте существующей макроэкономической и политической ситуации.

Результаты исследований. По данным Федеральной налоговой службы, систему уплаты ЕСХН на 1 января 2017 г. применяли 99,7 тыс. организаций, в том числе 75 тыс. индивидуальных предпринимателей и крестьянских (фермерских) хозяйств и 24 тыс. организаций. Причин, объясняющих популярность этого специального налогового режима, достаточно много:

низкая ставка налогообложения на разницу между доходами и расходами, составляющая всего $6 \%$;

отсутствие обязанности по уплате налога на имущество (до 1,1 \% от остаточной стоимости) [6];

отсутствие налога на прибыль (20 \%);

отсутствие обязанности по уплате налога на добавленную стоимость (НДС) при реализации своей продукции (в большинстве случаев $10 \%$, реже $18 \%$ );

упрощенное ведение бухгалтерского учета [3].

При этом до последнего времени ограничения на использование системы уплаты ЕСХН были минимальными и касались только численности персонала (до 300 человек). Этот налоговый режим обеспечил в 2016 г. поступление в консолидированные бюджеты регионов 11,4 млрд руб. Однако по объективным причинам многие сельхозтоваропроизводители отказывались от предоставленной возможности использовать этот инструмент государственной поддержки.

Во-первых, большинство сельскохозяйственных организаций реализуют свою продукцию крупным переработчикам, применяющим общую систему налогообложения (ОСН), которым крайне необходим входящий НДС к вычету. При этом сырье в структуре затрат переработчика может занимать до 90 \%. Например, если мукомольное предприятие будет осуществлять закупку зерна у сельскохозяйственных организаций, применяющих ЕСХН, то оно после вычета входного НДС (на коммунальные услуги, запчасти и оборудовании) должно будет перечислить в бюджет от общего объема реализации 7,5-8,5 \% в качестве НДС к доплате. Получается, что закупать сырье у плательщиков ЕСXН выгодно только небольшим переработчикам, также применяющим специальные налоговые режимы, например упрощенную систему налогообложения (УСH).

Во-вторых, даже если сельскохозяйственное предприятие осуществляет переработку собственной продукции, выпуская готовые к потреблению продукты, то оно всё равно вынуждено является плательщиком НДС, наличие которого является обязательным условием работы с подавляющим большинством торговых сетей.

Получается, что, с одной стороны, переработчики вынуждают сельхозтоваропроизводителей отказываться от ЕСХН, а, с другой - в условиях массового применения этого налогового режима они вынуждены за счет собственных ресурсов компенсировать значительную разницу между НДС от реализации и входящим НДС.

В итоге основными плательщиками ЕСХН являются:

1. Сельскохозяйственные организации, го- 
товые ценой на свою продукцию компенсировать переработчикам или закупщикам отсутствие включенного в цену НДС;

2. Поставщики сырья для небольших переработчиков, также применяющих специальные налоговые режимы;

3. Сельскохозяйственные организации, осуществляющие первичную или полную переработку своей продукции и реализующие ее конечным потребителям или мелкому ритэйлу, также применяющему специальные налоговые режимы (УСН и др.);

4. Крупные агрохолдинги, имеющие свои перерабатывающие мощности, работающие с замкнутым производственным циклом «от поля (фермы) и до прилавка», имеющие собственную фирменную розничную сеть, поставляющие свою продукцию большому количеству небольших частных магазинов или в государственные структуры, а также договорившиеся с крупными сетевыми магазинами о поставках без НДС.

В этих условиях сырьевые хозяйства агрохолдингов, птицефабрики, поставщики крупных переработчиков и экспортеров сельскохозяйственного сырья в абсолютном своем большинстве отказались от перехода на систему уплаты ECXН. До 2018 г. все эти организации применяли общую систему налогообложения $(\mathrm{OCH})$, одновременно с этим применяя в качестве сельхозтоваропроизводителя льготную нулевую ставку по налогу на прибыль [7]. Для многих отраслей это не приводило к большому увеличению налоговой нагрузки по следующим причинам.

Во-первых, нулевая ставка по налогу на прибыль организаций.

Во-вторых, исходящий НДС в размере 10 \% легко компенсируется большим входящим НДС в цене приобретаемых услуг и материалов. Например, хозяйство, занимающиеся растениеводством, с входящим восемнадцати процентным НДС приобретает: технику, запасные части, семена (10\%), ГСМ, услуги по ремонту и обслуживанию, сельхозхимию и удобрения и т.д. В менее выгодных условиях оказались хозяйства, производящие трудоемкую продукцию с высокой долей затрат на оплату труда.

Таким образом, при применении различных налоговых режимов для сельхозтоваропроизводителей и переработчиков сложилась крайне неоднозначная ситуация, которая уже на протяжении десятка лет требовала разрешения. В итоге, несмотря на первоначально отрицательные отзывы Минфина (письма Минфина России от 19.05.2016 № 03-07-14/28647, от 27.05.2016 № 03-07-14/30740) и Правительства, с 1 января 2018 г. налогоплательщики ЕСХН получили право уплачивать НДС. Причем более крупным с 2019 г. это будет фактически вменяться в обязанность [1]. Соответственно, сельскохо- зяйственные организации, чей доход по итогам 2018 г. превысит 100 млн руб., будут обязаны платить НДС. В последующем ежегодно порог будет снижаться на 10 млн руб. и к 2022 г. составит всего 60 млн руб.

C учетом этих изменений многовариантность систем налогообложения для сельскохозяйственных организаций сохранится и даже расширится. Будут сосуществовать следующие системы.

1. Сельскохозяйственные предприятия, применяющие ОСН. Список этих организаций также пополнят часть налогоплательщиков, ранее применяющих систему уплаты ЕСХH и имеющих годовую выручку более 60 млн руб.

2. В 2019 г. также останутся организации, индивидуальные предприниматели и крестьянские (фермерские) хозяйства, применяющие систему уплаты ЕСХH и не выплачивающие НДС. Ставка налога в 6 \% от разницы между доходами и расходами, упрощенный бухгалтерский учет, отсутствие необходимости администрирования НДС будут являться хорошими стимулами для выбора этого льготного налогового режима.

3. В 2019 г. появятся организации использующие систему налогообложения, которую можно описать как «ЕСХН+НДС». Сельскохозяйственные предприятия, которые выберут этот режим, будут платить и ЕСХH, и НДС, они также будут иметь право на вычеты по налогу на добавленную стоимость, как и предприятия, применяющие ОСН. С одной стороны, для этих предприятий действуют упрощенные правила бухгалтерского учета, с другой - на них полностью распространяются требования законодательства по администрированию НДС (ведение книги покупок и книги продаж, подача деклараций по НДС и т.д.). Они также как раньше будут платить ЕСХН. Получается, что, с одной стороны, будет вестись упрощенный бухучет, a, с другой - будет вестись практически полный налоговый учет. От уплаты налога на имущество налогоплательщики, перешедшие на схему «ЕСХН+НДС», будут освобождены.

Последний из представленных вариантов, скорее всего, будет применяться предприятиями при следующих условиях:

наличие среди покупателей предприятия крупных переработчиков и закупщиков, которые имеют принципиальный интерес к приобретению сырья только с включенным в его цену НДС;

наличие выручки в 2018 г. не более 100 млн руб., а к 2022 г. не более 60 млн руб.;

наличие достаточно большого потока затрат с включенным в них НДС (семена, ГСМ, запасные части, корма, удобрения и т.д.);

соответственно, низкая доля расходов на оплату труда в общей структуре затрат;

небольшая разница между доходами и при- 
нимаемыми к расчету ЕСХН доходами, иначе выгоднее применять льготную ставку по налогу на прибыль.

В итоге получается, что круг налогоплательщиков, применяющих новую систему «ЕСХН+НДС», будет достаточно ограниченным. По нашему мнению, вообще можно говорить о переходном характере этого режима налогообложения.

В то же время описанные выше изменения в законодательстве будут иметь и ряд отрицательных последствий.

Во-первых, многим сельскохозяйственным предприятиям, в том числе фермерским хозяйствам, придется столкнуться с необходимостью администрирования НДС, что значительно усложняет бухгалтерский и налоговый учет.

Во-вторых, введение практически поголовного НДС на продукцию сельскохозяйственных организаций приведет к увеличению налоговой нагрузки на отрасль за счет высокой трудоемкости сельскохозяйственного производства.

В-третьих, наибольшее увеличение налоговой нагрузки придется на крупные сельскохозяйственные предприятия и небольшие сельскохозяйственные агрохолдинги, которые, применяя систему уплаты ЕСХH, осуществляли переработку собственной продукции по принципу «от поля до прилавка» и имели в структуре затрат высокую долю расходов на оплату труда, свойственную как отраслям сельского хозяйства, так и пищевой промышленности. При этом ограниченность круга таких производителей позволит сделать эффект от принятых изменений практически незаметным.

Наиболее положительно изменения налогового законодательства повлияют на перерабатывающие и пищевые предприятия, которые за счет наличия «входного» НДС на сырье смогут значительно снизить свою налоговую нагрузку и направить свободные денежные средства на инвестиции в развитие производственных мощностей. В перспективе это может стимулировать внутренний спрос на сельскохозяйственное сырье.

В целом можно говорить о начале установления в России единой системы расчета и уплаты налога на добавленную стоимость для всей производственной цепочки АПК. Это очевидно приведет к увеличению налоговой нагрузки на отрасль, но, скорее всего, учитывая косвенный характер налога, будет переложено на потребителей. Получается, что государство отказывается от одного из действенных и, вместе с тем разрешенных ВТО, инструментов поддержки АПК. При этом происходит всё это на фоне увеличения так называемой неналоговой нагрузки на бизнес, например введение в 2017 г. системы «Платон». Однако и необходимость унификации применения НДС для преодоления «налогового разрыва» между переработчиками и производителями сельскохозяйственной продукции отрицать невозможно.
Для сохранения уровня динамики развития отечественного АПК при увеличении фискальной нагрузки, а также для его постоянной готовности к возможной отмене продовольственного эмбарго необходимо усилить государственную поддержку отрасли в рамках мер именно «зеленой» корзины ВТО [8]. Для этого, на наш взгляд, в первую очередь, необходимо:

не просто увеличить объем льготного кредитования предприятий АПК, но и упростить доступ к этому ресурсу, сделать механизм распределения этой поддержки более простым, прозрачным и понятным;

за счет поддержки производителей техники и технологий максимально способствовать техническому перевооружению АПК для увеличения производительности трудовых ресурсов;

максимально упростить доступ предприятий АПК к инструментам льготного лизинга сельскохозяйственной техники и автотранспорта;

в связи с резким удорожанием ресурса разработать механизм субсидирования приобретения дизельного топлива сельскохозяйственными предприятиями.

Заключение. В конечном итоге повышение уровня финансовой устойчивости именно пищевых и перерабатывающих предприятий положительно скажется на внутреннем продовольственном рынке, что будет способствовать развитию конкуренции на нем. В свою очередь, развитая отрасль производства продуктов питания это не только основа политики импортозамещения, но и фундамент для выхода на международный агропродовольственный рынок в качестве поставщика как сырья, так и уже готовых продуктов питания. Повышение фискальной нагрузки на сельскохозяйственные предприятия должно быть компенсировано при этом другими мерами государственной поддержки, желательно соответствующими «зеленой» корзине ВТО.

Также можно сделать вывод о том, что дальнейшей целью государственной фискальной политики в перспективе будет являться создание максимальных ограничений для применения льготных налоговых режимов предприятиями крупного, среднего, а также малого бизнеса. Необходимо быть готовым к тому, что право на льготное налогообложение будут иметь только небольшие частные или семейные микропредприятия.

\section{СПИСОК ЛИТЕРАТУРЫ}

1. Власти заставят часть аграриев платить дополнительный налог // РосБизнесКонсалтинг. - Официальный сайт. - Режим доступа: https://www.rbc.ru/ economics/16/11/2017/ 5a0c68e49a794721ba4841db.

2. Галимов А.Ф., Николаева А.С. Организация налогового учета по единому сельскохозяйственному налогу // Новая наука: От идеи к результату. - 2016. - № 12-1. C. $78-80$.

3. ЕСХН - единый сельхозналог 2017 // 1С-Старт: помогаем начать своё дело. - Режим доступа: https:// 
www.regberry.ru/nalogooblozhenie/ESHN.

4. Кузнещова О.Н. Учетно-аналитическое обеспечение расчетов по единому сельскохозяйственному налогу // Экономика и предпринимательство. -2015. № 5-1 (58-1). - С. 445-448.

5. Налоговый кодекс Российской Федерации (часть вторая). Глава 26.1. // СПС «Консультант Плюс». - Режим доступа: http://www.consultant.ru/document/cons doc_LAW_28165/ 6e115134a13db9e972d7d94237b5ed95f $\mathrm{cb} 0 \overline{0} \mathrm{~d} 14 /$.

6. О внесении изменений в части первую и вторую Налогового кодекса Российской Федерации и отдельные законодательные акты Российской Федерации: [Федер. закон: принят Гос. Думой 27 ноября 2017 г. N 335-Ф3 (последняя редакция)] // СПС «Консультант Плюс». - Режим доступа: http://www.consultant.ru/ document/cons_doc_LAW_283495/.

7. Ставка налога на прибыль для сельхозпроизводителей // Экономика и жизнь. - Режим доступа: https:// www.eg-online.ru/news/345816/.

8. Суханова И.Ф., Лявина М.Ю. Совершенствование системы господдержки животноводства как инструмен- та политики импортозамещения // Аграрный научный журнал - 2017. - № 12. - С. 92-95.

9. Филиппова А.А. Единый сельскохозяйственный налог // Новая наука: Современное состояние и пути развития. - 2017. - Т. 1. - № 3. - С. 165-168.

10. Шевцова Т.П., Белокопытов А.В. Единый сельскохозяйственный налог как инструмент регулирования эффективности сельскохозяйственного производства // Вестник Российского государственного аграрного заочного университета. - 2016. № 21 (26). - С. 94-99.

Суханова Ирина Федоровна, д-р экон. наук, проф. кафедры «Маркетинг и внешнеэкономическая деятельность», Саратовский государственный аграрный университет имени Н.И. Вавилова.

Россия. 410012, г. Саратов, Театральная пл., 1.

Тел.: (8452) 23-72-60.

Алиев Максим Игоревич, канд. экон. наук, финансовый менеджер, ООО «Торговая группа Союз». Россия.

180004, г. Псков, Железнодорожная ул., 43.

Тел.: (8112) 72-23-26.

Ключевые слова: налогообложение; единый сельскохозяйственный налог; налог на добавленную стоимость.

\title{
DEVELOPMENT OF AGRICULTURAL AND PROCESSING ENTERPRISES: PROBLEMS AFTER CHANGES OF FISCAL LEGISTATION IN RF
}

Sukhanova Irina Fedorovna, Doctor of Economic Sciences, Professor of the chair "Marketing and International Economic Activity", Saratov State Agrarian University named after N.I. Vavilov. Russia.

Aliev Maksim Igorevich, Candidate of Economic Sciences, financial manager of LLC «Torgovaya gruppa Soyuz». Russia.

Keywords: taxation; unified agricultural tax; value added tax.
Various options of systems of the taxation applied in the enterprises of agro-industrial complex are considered. The analysis of consequences of changes of the fiscal legislation regarding the system of collection of a unified agricultural tax is made. Macroeconomic consequences of introduction of system of the taxation with use of a value added tax by the principle "from the field to a counter" are studied.

удк 338.43

\section{АНАЛИЗ ОЦЕНКИ ЭФФЕКТИВНОСТИ РЕАЛИЗАЦИИ ГОСУДАРСТВЕННОЙ ПРОГРАММЫ РАЗВИТИЯ СЕЛЬСКОГО ХОЗЯЙСТВА В РОССИИ}

\author{
УМЕРОВА Светлана Александровна, Саратовский социально-экономический институт \\ (филиал) РЭУ им. Г.В. Плеханова
}

САНИНСКИЙ Сергей Александрович, Саратовский социально-экономический институт (филиал)РЭУ имени Г.В. Плеханова

Анализируется Государственная программа развития сельского хозяйства и регулирования рынков сельскохозяйственной продукиии, сыръя и продоволъствия на 2013-2020 годы (далее - Государственная программа), а в том числе методология оценки эффективности указанной программы. Выявлены недостатки методики оценки эффективности Государственной программы, связанные с субъективностью имеющихся нормативов; отсутствием использования в расчетах корреляционно-регрессионных моделей, позволяющ,их выявить и учесть зависимость полученнъх результатов от изменения отдельнъх факторов и условий среды; неоптимальным расчетом комплексного показателя эффективности реализации Государственной программы. Авторы предлагают ранжировать основные индикаторы Государственной программы по характеристике выражаемых явлений и процессов: экономическая эффективность, социальная эффективность и бюджетная эффективность, и признакам, раскрывающим природу измеряемого объекта: количественные показатели и качественные показатели. Рекомендуется внести соответствующие изменения в методику расчета основных индикаторов Государственной программы.

Введение. Агропромышленный комплекс важнейший межотраслевой комплекс национальной экономики, обеспечивающий удовлетворение потребностей в продовольственных товарах как основы жизнедеятельности людей и воспроизводства трудовых ресурсов, потребительских това- рах из сельскохозяйственного сырья и продукции производственного назначения и в конечном итоге - продовольственную безопасность России [3]. Агропромышленный комплекс также обеспечивает самозанятость населения, развитие сельских территорий, сохранение сельского уклада жизни, 